\title{
Produção de tubos de concreto por centrifugação
}

Spin for concrete pipe production

André Luis de Brito Baptista'

Luiz de Araujo Bicalho ${ }^{2}$

Roberto de Oliveira Magnago ${ }^{3}$

\footnotetext{
1 Aluno do Programa de Mestrado Profissional em Materiais MeMat - UniFOA. andrebbatista@ig.com.br

2 Prof. Dr. Mestrado em Materiais do UniFOA. bicalholuiz@uol.com.br

3 Prof. Dr. Mestrado em Materiais do UniFOA. roberto.magnago@gmail.com
}

\section{RESUMO}

Neste trabalho é apresentada uma revisão do estado da arte da produção de tubos de concreto, obtidos por centrifugação. Faz-se também uma revisão do conceito de concreto armado e protendido. Mostramse detalhes do processo de produção e valores das características do material. Os tubos centrifugados apresentam vantagens em relação aos estáticos, em termos de propriedades mecânicas, custos e contribuição ao meio ambiente.

\section{Palavra-chave}

Tubo; concreto armado; centrifugação.

\section{ABSTRACT}

This paper presents a review of the state-of-the art production of concrete pipes, obtained by centrifugation, it is also a review of the concept of reinforced and prestressed concrete. It shows details of the production process and the values of material characteristics. The centrifuged tubes have advantages over static in terms of mechanical properties, cost and contribution to the environment.

\section{Keywords}

Pipe; reinforced concrete; centrifugation.

\section{Como você deve citar?}

BAPTISTA, André Luis de Brito; BICALHO, Luiz de Araujo; MAGNAGO, Roberto de Oliveira. Produção de tubos de concreto por centrifugação. Cadernos UniFOA, Volta Redonda, n. 27, p. 33-44, abr. 2015. 


\section{INTRODUÇÃO}

O homem sempre se utilizou de materiais para satisfazer suas necessidades. Nos tempos mais remotos, os materiais serviam para obtenção de utensílios de caça, de uso doméstico e para o vestuário. Depois de extraídos da natureza, eram utilizados quase que diretamente em suas aplicações, com pouco ou quase nenhum processamento $[1,2]$. Com o passar dos tempos, o homem foi dominando o conhecimento a respeito dos materiais e seu processamento. Pode-se visualizar na Tabela I, a cronologia da utilização dos materiais no decorrer do tempo.

Tabela 1 - Evolução do uso de materiais pelo homem [1]

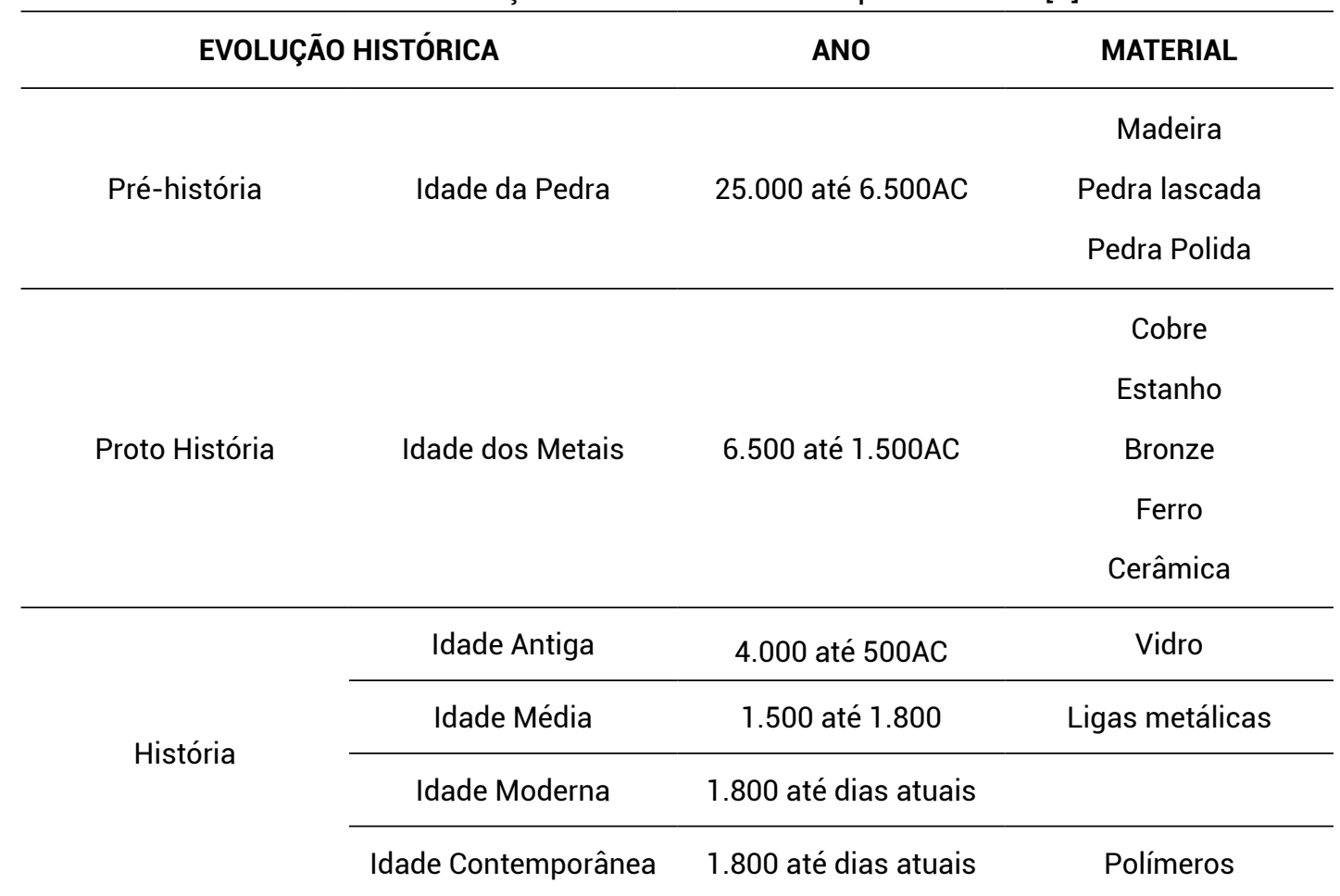

O concreto é o segundo material mais consumido pela humanidade, superado apenas pela água [3]. Um dos motivos desse elevado consumo é pelo fato de poder comparar-se a uma rocha artificial, que pode ganhar formas e volumes, de acordo com as necessidades de cada obra. Os concretos são destinados para recobrir ou não estruturas de ferro/aço armadas, para a construção dos alicerces, pilares, vergas etc, dando forma aos produtos que serão utilizados no processo construtivo [4].

De maneira simplificada, podemos definir concreto como uma mistura em proporções prefixadas de um aglutinante/aglomerante com água e um agregado/aglomerado constituído de areia e pedra, de sorte que venha a formar uma massa compacta e de consistência mais ou menos plástica, endurecendo com o tempo. É uma mistura íntima e homogênea de um cimento, um agregado fino, um agregado grosso e água que endurece quando seca. Conforme a necessidade, pode-se acrescentar aditivos que influenciam as características físicas e químicas do concreto fresco ou endurecido, como os: aceleradores, retardadores, incorporadores de ar, plastificantes, superplastificantes e seus derivados. Após a mistura do cimento com os agregados e aditivos, o produto é moldado em formas para a cura, que é a fase de secagem do concreto (Figura 1). 0 concreto, quando armado com ferragens passivas, recebe 0 nome de concreto armado e, quando for armado com ferragens ativas, ou seja, pré-esforçadas, recebe o nome de concreto protendido [5]. Os tubos de concreto produzido para coleta e transporte das águas pluviais, esgoto sanitário e efluente industriais, usados também em reservatórios, postes, estacas, pilares, assim como as aduelas de concreto utilizadas para a implementação de sistema de drenagem 
pluvial (galerias de águas pluviais), todos produzidos nesse segmento industrial, são imprescindíveis para o meio ambiente e garantia de qualidade de vida (Figura 2).

Figura 1 - Produção do concreto [4]

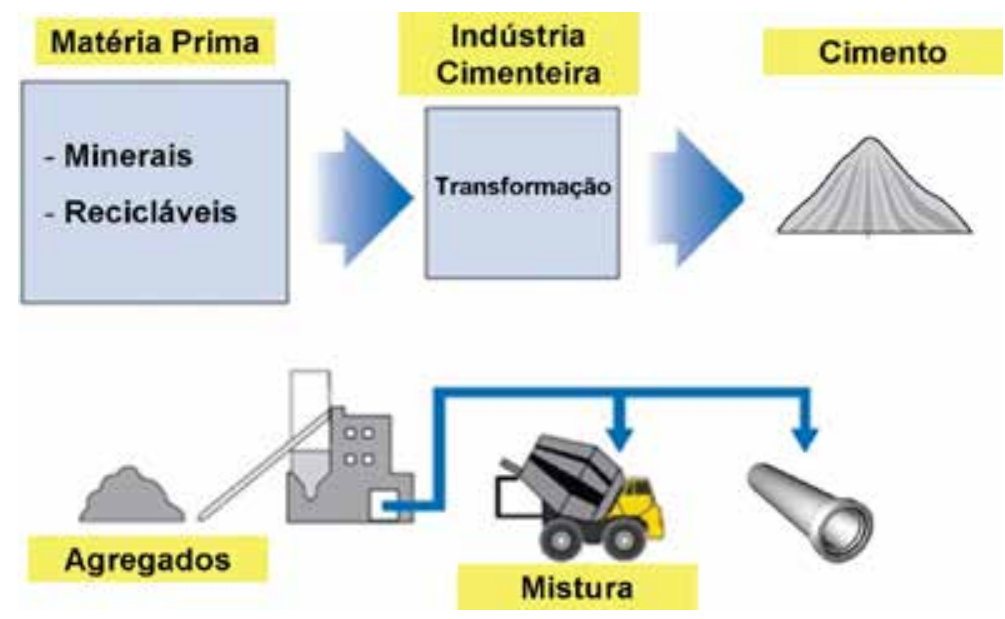

As peças centrifugadas são fabricadas em concreto simples ou armado, com adensamento por centrifugação de alta velocidade em formas metálicas, cilíndricas e vazadas nas extremidades [6]. No seu interior, são depositadas as armações e o concreto. As formas são posicionadas sobre os roletes que giram em alta velocidade ao redor do seu eixo longitudinal de seção circular, ao final do qual é ligeiramente levantada em um dos lados para o escoamento do excesso de águas e finos. 0 primeiro passo é realizar a montagem da armação. Em seguida, é feito o lançamento do concreto fresco e o fechamento da forma, quando, então, esta é transportada até o setor de centrifugação. 0 processo de centrifugação consiste na rotação de formas metálicas a alta velocidade em torno do seu eixo longitudinal com concreto fresco. Através da força de centrifugação, são alcançadas características ímpares ao se atingir uma força de compactação de até 50 vezes a força da gravidade [6]. 0 concreto centrifugado é um produto muito difundido mundialmente para fabricação de elementos em concreto destinados a ambientes altamente agressivos e, também, em sistemas construtivos que priorizem a segurança. São muitas as vantagens que o processo de centrifugação oferece. Dessa maneira, o processo beneficia projetos com necessidades estruturais ou de durabilidade muito específicos. A figura 2 mostra foto de exemplos de tubos centrifugados de concreto [7].

Figura 2 - tubos centrifugados de concreto [6]
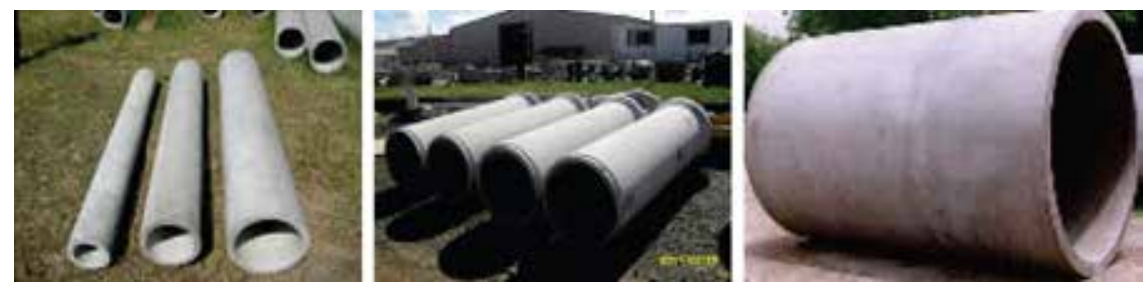

\section{CONCEITO DE CONCRETO ARMADO}

0 concreto é um material que apresenta alta resistência às tensões de compressão da ordem de $200 \mathrm{Kgf} / \mathrm{cm}^{2}(20 \mathrm{MPa})$ a $500 \mathrm{Kgf} / \mathrm{cm}^{2}(50 \mathrm{MPa})$, porém, apresenta baixa resistência à tração (cerca 
de $10 \%$ da sua resistência à compressão) [8]. Assim sendo, é imperiosa a necessidade de se juntar ao concreto um material com alta resistência à tração, com o objetivo desse material, disposto convenientemente, resistir às tensões de tração atuantes. Com esse material composto, surge, então, o chamado "concreto armado", no qual as barras da armadura absorvem as tensões de tração e o concreto absorve as tensões de compressão. Em resumo, pode-se definir o concreto armado como "a união do concreto simples e de um material resistente à tração (envolvido pelo concreto) de tal modo que ambos resistam solidariamente aos esforços solicitantes" [8]. A armadura do concreto armado é chamada "armadura passiva" (figura 3 e 4), o que significa que as tensões e deformações nela aplicadas devem-se exclusivamente aos carregamentos aplicados nas peças onde está inserida (armadura passiva é "qualquer armadura que não seja usada para produzir forças de protensão, isto é, que não seja previamente alongada). 0 trabalho conjunto do concreto e do aço é possível, porque os coeficientes de dilatação térmica dos dois materiais são praticamente iguais [9].

Figura 3 - armação de aço do tubo [8]

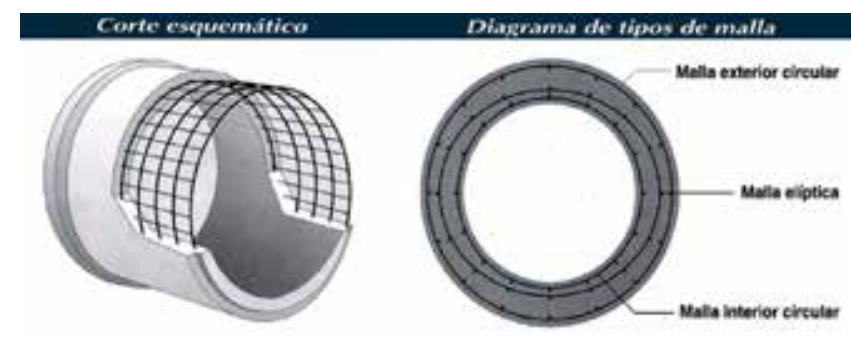

Figura 4 - Armação de aço e tubo de concreto centrifugado [9]

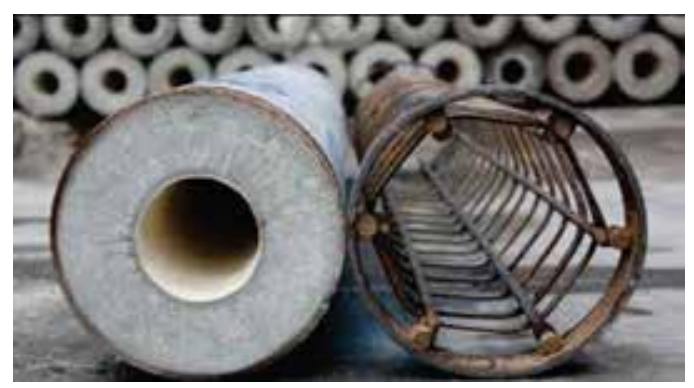

\section{CONCEITO DE CONCRETO PROTENDIDO}

A protensão é o artifício de introduzir, numa estrutura, um estado prévio de tensões, de modo a melhorar sua resistência ou seu comportamento sob ação de diversas solicitações, com a finalidade de, em condições de serviço, impedir ou limitar a fissuração e os deslocamentos da estrutura e propiciar o melhor aproveitamento de aços de alta resistência no estado limite último. No sistema de prétensão, se faz o estiramento (tracionamento) da armadura ativa dentro do regime elástico, antes que haja a aderência entre o concreto e aço. Terminado o estiramento, o concreto é lançado para envolver a armadura de protensão e dar a forma desejada à peça. Decorridas algumas horas ou dias, tendo o concreto a resistência mínima necessária, o esforço que estirou a armadura é gradativamente diminuído, o que faz com que a armadura aplique esforços de compressão ao concreto, ao tentar voltar ao seu estado inicial de deformação zero [10]. Outro sistema de protensão é a pós-tensão, em que a força de protensão é aplicada após a peça estar concretada e com o concreto com resistência suficiente para receber a força de protensão. As resistências de concreto protendido são duas a três vezes maiores que 
as utilizadas em concreto armado. Como resultado final, o concreto protendido permite fabricar peças maiores que o concreto armado convencional. 0 concreto pré-esforçado ou concreto protendido é um método eficiente de se ultrapassar a fraca resistência à tensão que o concreto possui. Ao pré-esforçar o aço, cria-se uma carga de aperto que faz com que se crie uma força de compressão que compensa a tensão que o concreto exibiria face à carga [10].

\section{PRODUÇÃO DE TUBOS DE CONCRETO CENTRIFUGADOS}

\subsection{O Concreto Centrifugado}

A centrifugação consiste em aplicar altas rotações num material em torno de um eixo fixo. Isso ocasiona a segregação de elementos de uma amostra, de acordo com as massas específicas de cada componente. Na construção civil, o primeiro processo foi utilizado em 1907, para a fabricação de postes de concreto com a concepção da primeira centrífuga pela empresa Schlosser. A compactação do concreto por meio da centrifugação consiste na aplicação de alta rotação ao concreto confinado em um molde metálico de seção geométrica desejada. Esse ciclo gera uma força centrífuga que projeta o concreto contra o molde a uma resultante de, aproximadamente, 30 vezes a aceleração da gravidade, conferindo alta compacidade à estrutura e uma seção vazada. Durante o processo de centrifugação, os componentes mais densos do concreto são orientados à superfície externa do elemento, garantindo uma superfície lisa e compacta. Por atribuir ao elemento características físico-mecânicas e estéticas diferenciadas, em países como Japão, Malásia, Itália, Estados Unidos, Rússia e Alemanha, essa técnica é difundida para fabricação de elementos em concreto destinados a ambientes altamente agressivos e utilizada para a produção de postes, estacas, vigas, pilares, torres eólicas e dutos para estruturas terrestres e marítimas. É possível obter geometrias externas variadas de acordo com a definição do molde, conforme Figura 5 . Outra grande vantagem é que, de acordo com as necessidades estruturais ou de durabilidade, onde o elemento estará submetido, o processo de centrifugação permite facilmente variar a espessura da parede do elemento vazado, seja ele, poste, estaca, coluna ou viga.

Figura 5 - Perfis de tubos centrifugados de concreto [7]
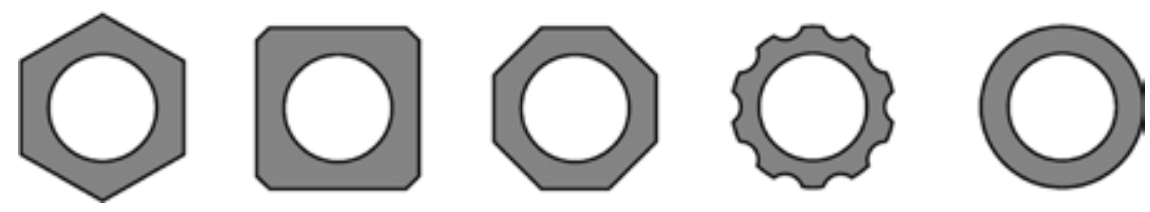

\section{PROCESSO DE PRODUÇÃO DE ELEMENTOS CENTRIFUGADOS}

O Processo de fabricação segue os seguintes passos (Figura 6): corte, dobra e endireitamento de fios de aço, montagem da armação. A montagem é feita de maneira manual, limpeza da forma metálica, montagem da armação na forma, dosagem de concreto, lançamento do concreto. 0 lançamento de concreto é efetivado por meio de caçambas que despejam o concreto acima sobre a forma, fechamento da forma, centrifugação, cura a vapor, desenforma. 
Figura 6 - Fluxograma da produção de tubos centrifugados de concreto

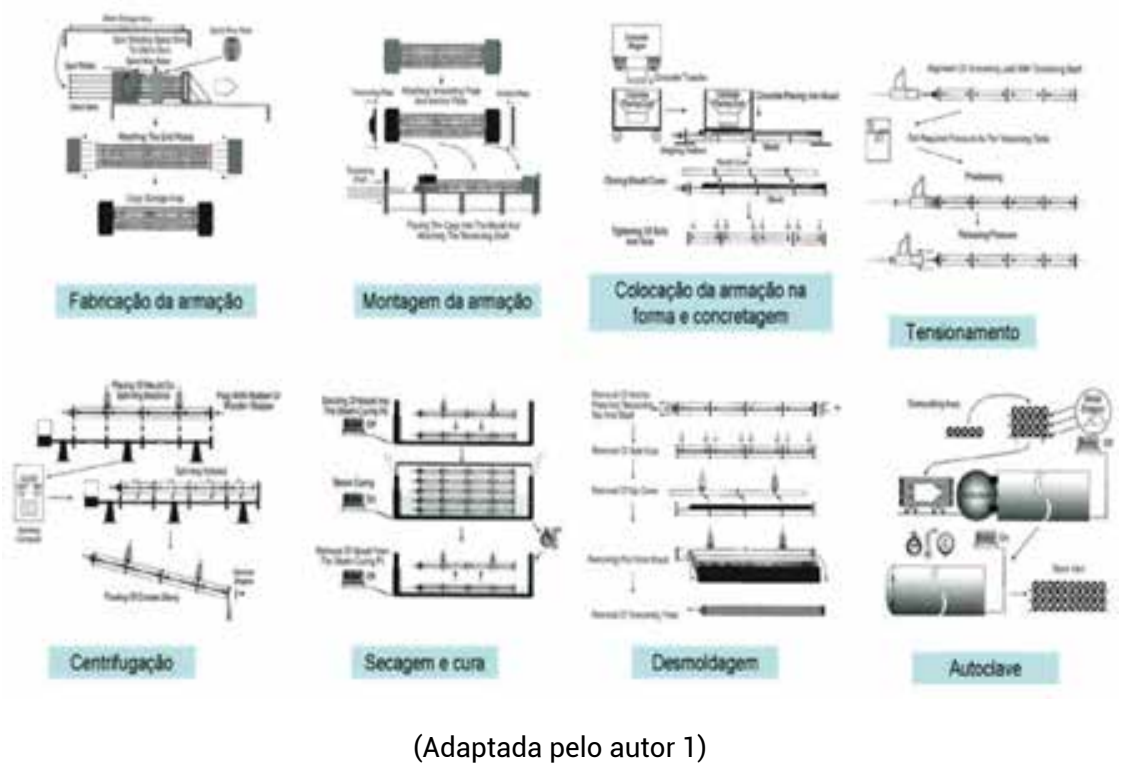

A fabricação de elementos de concreto consiste na montagem da armação sobre uma forma lubrificada com desmoldante (Figura 7). Os elementos podem ser simplesmente armados ou protendidos por pré-tensionamento de cordoalhas ou fios contra as formas autoportantes. De acordo com a geometria desejada, é lançado um volume pré-determinado de concreto sobre a forma, que, então, é fechada através de parafusos ou cunhas de grande resistência e, caso necessário, protendida. A forma é, então, encaminhada até a centrífuga. Existem dois tipos de centrífuga: por gravidade, em que a forma é apoiada sobre um conjunto de rodas que transferem o movimento através do atrito; ou Schlosser, quando as formas são colocadas numa máquina composta por conjuntos de tambores que confinam a forma e a rotaciona num mesmo eixo. A Figura 8 apresenta os dois tipos de centrífuga citados.

Figura 7 - Fabricação da armação e montagem na forma [11]

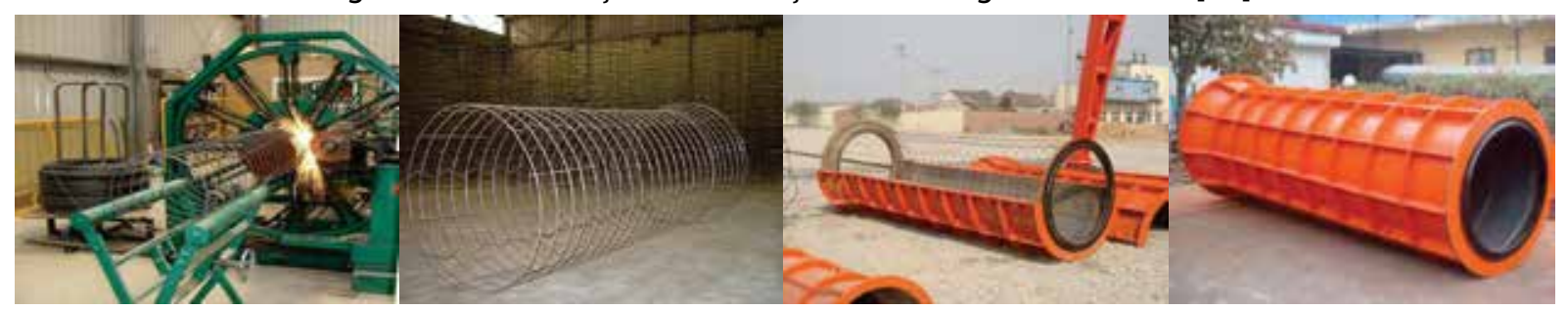

Figura 8 - Modelos básicos de centrifugadoras para tubos de concreto [7]

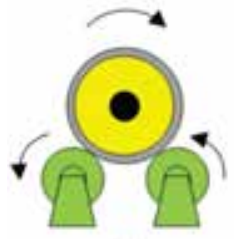

(a)

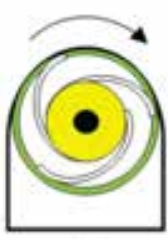

(b)

(a) centrífuga de gravidade e (b) centrífuga Schlosser 
As formas são submetidas ao processo de centrifugação por alguns minutos pré-determinados. São empregadas basicamente duas velocidades de centrifugação. Na primeira, em velocidade reduzida, o concreto fresco e plástico é misturado e distribuído de maneira uniforme ao longo da forma. Logo após, na rotação máxima, o concreto é projetado contra um molde metálico, resultando uma aceleração equivalente a 30 vezes a força da gravidade. A figura 9 mostra a sequência de formação da peça centrifugada. Como consequência, obtêm-se elementos vazados (ocos) e com as distâncias entre os agregados e outras partículas sólidas são reduzidas, e partes da água, além de partículas finas de baixa resistência são expulsas do concreto. Nesse momento, o concreto atinge um dos mais altos graus de compacidade dentre os diversos métodos de adensamento existentes. Os materiais submetidos à elevada força centrífuga tendem a se ordenar segundo o peso específico de cada componente do traço. Devido ao seu peso específico, uma parte do cimento envolve toda a superfície externa do elemento, formando uma capa externa extremamente lisa, de alto coeficiente de impermeabilidade, alta resistência contra ações químicas e físicas e, consequentemente, alta durabilidade. Internamente, devido a sua menor densidade, a água é impulsionada para fora do concreto, carreando os elementos finos leves. Com a redução de relação água/cimento $(\mathrm{a} / \mathrm{c})$ e de materiais finos, o concreto centrifugado obtém elevada característica de resistência à compressão. A alta energia de compactação permite ao processo utilizar concretos com uma taxa elevada de agregados graúdos, comparando ao modo de dosagem de traços para concreto adensado por vibração. Isso melhora o módulo de elasticidade e proporciona baixa porosidade. A centrifugação ainda melhora a aderência entre o aço e o concreto, baixa retração e uma superfície lisa e densa. Fisicamente, a centrifugação resulta num decréscimo da porosidade, com aumento da homogeneidade e da resistência. Após a centrifugação, aplica-se um ciclo de cura a vapor por um determinado intervalo de tempo. Após esse período, os elementos podem ser desmoldados.

Figura 9 - Fases da centrifugação [7]:

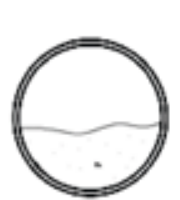

(a)

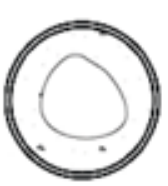

(b)

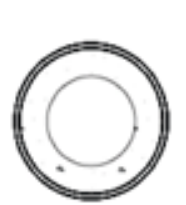

(e)

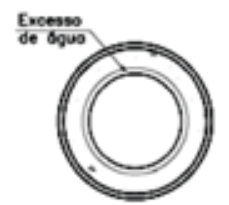

(d)

a) Distribuição do concreto; b) Formação da seção vazada; c ) Compactação do concreto; d) Expulsão da água por compactação

Figura 10 - Produção de tubos retos [11]

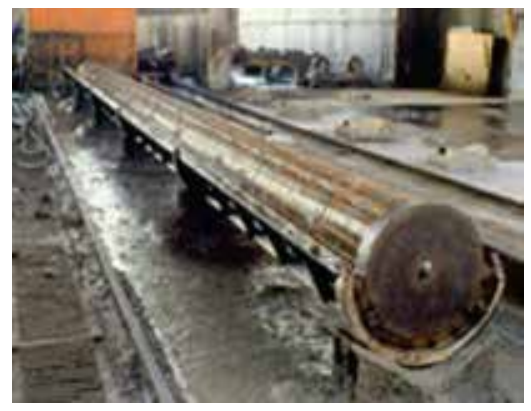

Forma com armação

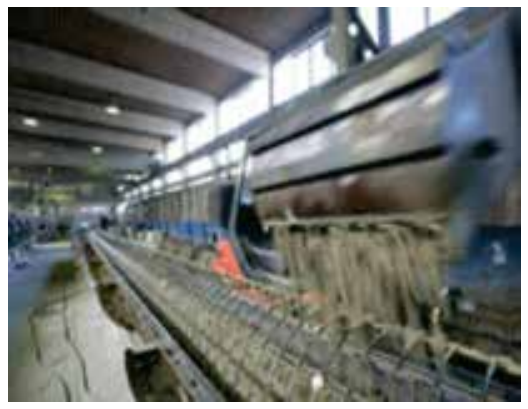

Enchimento do molde mecanizado

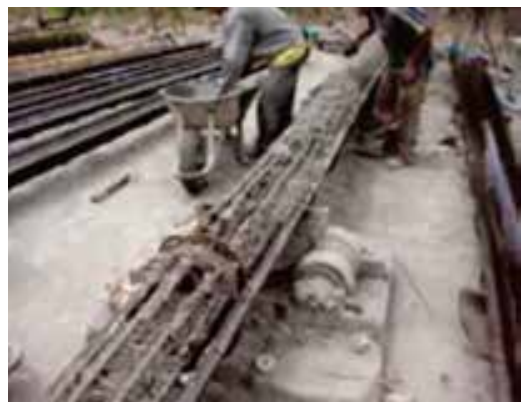

Enchimento do molde manual 


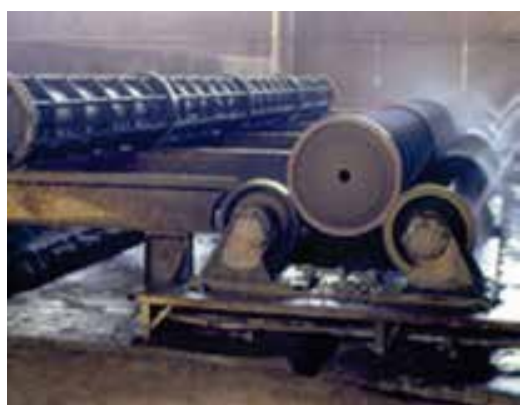

Centrifugação

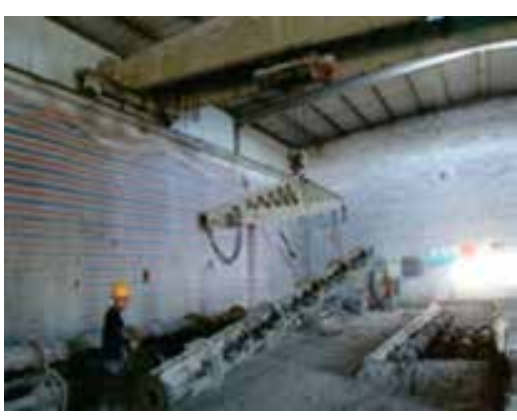

Cura

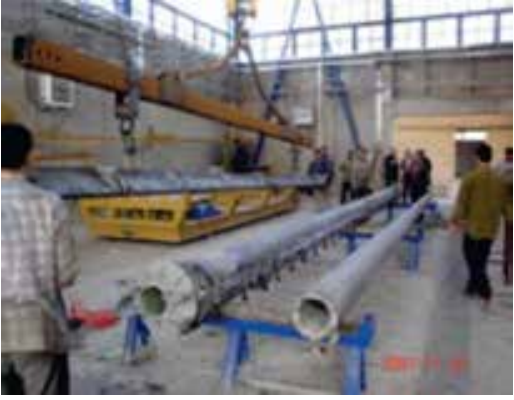

Desmoldagem

Figura 11 - Fabricação de tubos de grande diâmetro com concreto protendido [11]

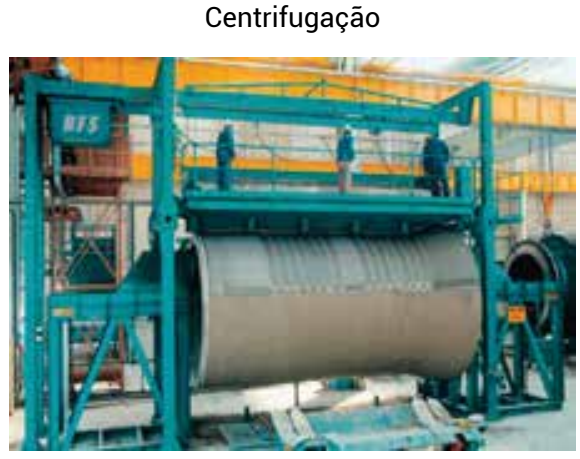

Protensão com malha de aço

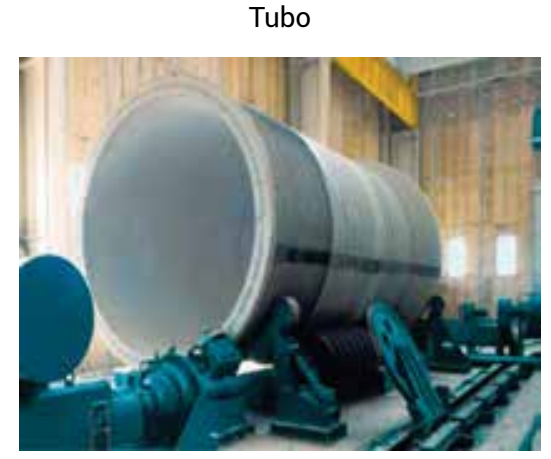

Protensão com fio de aço

\subsection{Excesso de água}

Internamente, devido a sua menor densidade, a água em excesso necessária para a reação do cimento é impulsionada para fora do concreto, carregando os elementos finos. Com a redução de relação água/cimento e de materiais finos, o concreto centrifugado obtém elevada característica de resistência à compressão, módulo de elasticidade e baixa porosidade. Assim, podemos citar algumas das características conferidas aos elementos de concreto centrifugado: maior impermeabilidade superficial; maior resistência mecânica; maior segurança em meio ambiente agressivo; alta durabilidade sob efeito de molhagem e secagem (variação de nível d'água); estética superficial diferenciada; possibilidade de inspeção do elemento em função da seção vazada, durante a produção, instalação ou mesmo após a instalação.

\subsection{Processo de Cura a Vapor}

Após submeter o concreto ao processo de centrifugação, as estacas são transportadas para o setor de cura a vapor. $O$ vapor oferece as condições ideais para a hidratação do cimento e as vantagens obtidas nesse processo são: a considerável redução de fissuras provenientes da retração do concreto; o ganho acelerado de resistência; maior segurança em meio ambiente agressivo; melhoria do módulo de elasticidade e durabilidade, ao reduzir significativamente a geração de poros, tornando a superfície mais resistente a agentes agressivos. Após a cura do concreto, os elementos pré-fabricados são desformados e mantidos em estoque durante 7 dias, até atingir a resistência adequada para o transporte e montagem.

\subsection{Contribuição do Processo de Centrifugação}

Por se tratar de estruturas em contato permanente com a água, o concreto deve resultar numa estrutura bem compacta e com baixa permeabilidade. 0 processo de adensamento do concreto por 
centrifugação consiste em aplicar altas rotações no concreto fresco dentro de um molde metálico em torno de um eixo fixo. Os materiais submetidos à elevada força centrífuga tendem a se ordenar segundo o peso especifico de cada componente, do maior para o menor. Devido ao maior peso específico do cimento $\left(y \approx 3,05 \mathrm{~g} / \mathrm{cm}^{3}\right)$, uma parte adere à face interna do molde metálico, formando uma capa externa lisa com baixo coeficiente de permeabilidade; em seguida, dispõem-se uma camada densa de concreto formada pelos agregados $\left(\gamma \approx 2,70 \mathrm{~g} / \mathrm{cm}^{3}\right)$. Internamente, devido a sua menor densidade, a água livre e impulsionada para fora da mistura de concreto, carreando os elementos inertes e leves $(\gamma \approx 1,00$ a 1,50g/ $\mathrm{cm}^{3}$ ). $\mathrm{O}$ fato de o concreto ser projetado por uma forca centrífuga contribui para um maior confinamento do concreto com as barras da armação, proporcionando melhor aderência. Para o traço utilizado no projeto, o processo de centrifugação contribuiu (Tabela II) para a diminuição da água livre da mistura, através da redução do fator $\mathrm{a} / \mathrm{c}$, incrementando em $14 \%$ a resistência à compressão e modificando a formação e conexão dos capilares. Isso possibilita o aumento da massa especifica do concreto, que somado ao maior teor de agregado graúdo utilizado, resulta num incremento do modulo de elasticidade. A energia de compactação devido à forca centrífuga permite ao processo utilizar concretos com elevadas taxas de agregados graúdos.

Tabela 2 - Efeitos do processo de centrifugação ao concreto fresco

\begin{tabular}{ccc}
\hline \multirow{2}{*}{ Parâmetros do Concreto } & \multicolumn{2}{c}{ Centrifugação } \\
\cline { 2 - 3 } & Antes & Depois \\
\hline Fator a/c & 0,40 & 0,34 \\
\hline Massa Específica $(\mathrm{Kg} / \mathrm{m} 3)$ & 2390 & 2530 \\
\hline Resistência à Compressão $(\%)$ & 100 & 114 \\
\hline
\end{tabular}

\subsection{Características Mecânicas}

Os valores de resistência estão apresentados na Tabela III e na figura 20. A resistência vai aumentando com o tempo pós fabricação, até o máximo de 30 dias, como mostrado na Tabela IV .

Tabela 3 - Características mecânicas de tubos centrifugados de concreto

\begin{tabular}{|c|c|c|c|}
\hline Parâmetros do Concreto & Norma & & Valores \\
\hline \multirow{2}{*}{ Resistência à Flexão } & \multirow{2}{*}{ ASTM C-293 } & $24 \mathrm{~h}$ & mín 600 a 800psi \\
\hline & & 28dias & mín 1080 a 1200psi \\
\hline \multirow{2}{*}{ Compressão } & \multirow{2}{*}{ ASTM C-109 } & $24 \mathrm{~h}$ & mín 3000 a 5000psi \\
\hline & & 28dias & mín 8000 a 11500psi \\
\hline Tração & ASTM C-496 & & 682 à 700psi \\
\hline
\end{tabular}




\begin{tabular}{lll}
\hline Cisalhamento & ASTM C-882 & 2100 a 1720 psi \\
\hline
\end{tabular}

Figura 20 - Curvas do comportamento mecânico do concreto centrifugado
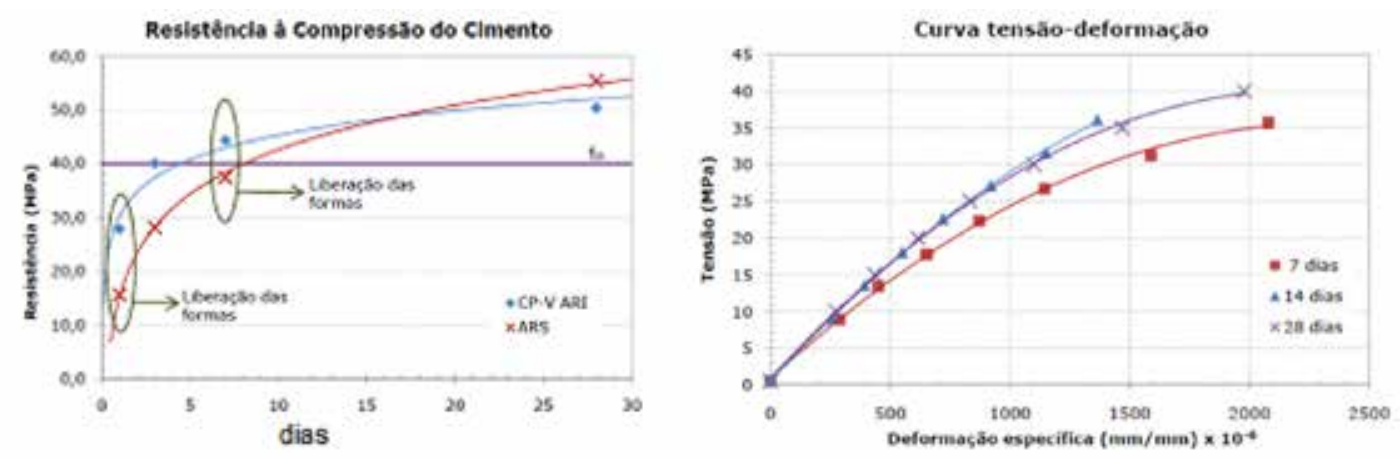

Tabela 4 - Aumento da resistência em \% com o tempo

\begin{tabular}{ccccc}
\hline \multirow{2}{*}{ TIPO } & \multicolumn{5}{c}{ CRESCIMENTO (\%) } \\
\cline { 2 - 5 } & 1 dia & 3 dias & 7 dias & 28 dias \\
\hline CP-V ARI & 51,1 & 78,0 & 86,5 & 100 \\
\hline ARS & 24,5 & 49,0 & 64,7 & 100 \\
\hline
\end{tabular}

\section{CONSIDERAÇÕES FINAIS}

A pedra é empregada nas construções desde a antiguidade. Egípcios, gregos e romanos utilizaram largamente a pedra como material de construção, em obras que, até hoje, são monumentos, como as pirâmides egípcias, os templos gregos e os arcos romanos. 0 emprego do concreto armado já é bem mais recente, cerca de pouco mais de um século. Um material de construção deve apresentar duas qualidades principais: resistência e durabilidade. A pedra tem durabilidade muito grande, praticamente ilimitada e oferece elevada resistência aos esforços de compressão, mas baixa resistência à tração. A madeira e o aço, materiais largamente utilizados na construção, apresentam algumas deficiências particulares, a saber: a madeira, com resistência de tração e compressão pouco elevadas e durabilidade limitada e, o aço, apesar da excelente resistência aos esforços de tração e compressão, está sujeito a deteriorar-se com o tempo.

Pode-se imaginar que o concreto armado tenha surgido com o desejo de gerar um tipo de construção que, utilizando uma "pedra" artificial, apresentasse a durabilidade da pedra natural, tivesse a vantagem de ser fundido nas dimensões desejadas e, associando o aço a essa "pedra" artificial, aproveitasse a alta resistência desse material, ao mesmo tempo em que, protegendo-o, aumentasse sua durabilidade. Atualmente, os tubos de concreto são produzidos em várias formas para atender a carência de muitas áreas, podendo ser utilizada em variadas condições e funções, além da drenagem de águas pluviais e sistemas de esgoto sanitário. Ao longo do tempo, têm surgido produtos alternativos, entretanto não conseguem atender a todas as características e vantagens dos tubos de concreto.

Os tubos de concreto se apresentam como um produto de qualidade consolidada com relação à sua durabilidade, resistência mecânica, facilidade de execução, manutenção e disponibilidade de fornecimento dentro das exigências de mercado, verificando-se que, desde a antiguidade, o concreto foi o primeiro substituto natural da pedra e que, muitas obras executadas no início do século passado encontram-se em operação, até hoje, com desempenho adequado. Os fabricantes nacionais dispõem de máquinas modernas e flexíveis, capazes de produzir os mais variados diâmetros com controle total da qualidade do produto final. Devido às fábricas de tubos de concreto situarem-se próximas do local 
das obras, em geral, são responsáveis pelo desenvolvimento local, com geração de empregos e arrecadação de impostos. Aliado às vantagens anteriores, relativas aos tubos de concreto, cabe ressaltar que o concreto é um material totalmente reciclável, não tóxico e não contaminante do meio ambiente, adequando-se, dessa maneira, a todas as exigências do ponto de vista ambiental, propiciando uma melhor qualidade de vida.

\section{CONCLUSÃo}

Os produtos centrifugados são aplicados onde se requer um desempenho superior de utilização. É 100\% ecológico por permitir utilizar toda a matéria-prima reciclada, incluindo o aço, que é oriundo de redução por biomassa.

Os tubos centrifugados exibem como vantagens principais : estrutura mais densa, menor nível de porosidades, maior ancoramento entre massa e estrutura metálica, resistência às tensões mais elevada, maior resistência às intempéries, com custo $40 \%$ menor que os outros processos. Sua duração é 10 anos maior que os tubos fabricados pelos processos estáticos.

\section{AGRADECIMENTOS}

Ao Prof. Claudinei dos Santos, pelo incentivo, exemplo de dedicação e trajetória de vida. 


\section{REFERÊNCIAS BIBLIOGRÁFICAS}

[1] PASCOALI, S. - Tecnologia dos Materiais I - Centro Federal de Educação Tecnológica de Santa Catarina - julho, 2008.

[2] PAVANATI, H. C. - Introdução à Tecnologia dos Materiais - Instituto Federal de Santa Catarina , Departamento Acadêmico de Metal-mecânica - Florianópolis, novembro de 2010.

[3] HAGEMANN, S. E. - Materiais de Construção Básicos - Instituto Federal Sul-Rio-Grandense Universidade Aberta do Brasil - 2011.

[4] CARVALHO, J. D. N. - Sobre as Origens e Desenvolvimento do Concreto - Revista Tecnológica, v. 17, p. 19-28, 2008.

[5] MOREIRA, A. R. - Tecnologia do Concreto - Centro Federal de Educação Tecnológica do Paraná Departamento Acadêmico de Construção Civil - Engenharia de Produção Civil - 2009.

[6] JORGE, A. L. A. - Aplicação de Tubos Cerâmicos na Coleta e Transporte de Esgotos Sanitários Associação Latino Americana dos Fabricantes de Tubos Cerâmicos, 28 de março de 2008.

[7] GOBBO, P.H.; MEDRANO,M.L.O.; UEHARA,F.N. - Propriedades Físico-Mecânicas do Elemento de Concreto Centrifugado - ANAIS DO 52 ${ }^{\circ}$ CONGRESSO BRASILEIRO DO CONCRETO - Outubro - 2010.

[8] BASTOS, P. S. S. - Fundamentos do Concreto Armado - Universidade Estadual Paulista- UNESP Campus de Bauru/SP - Faculdade de Engenharia - Departamento de Engenharia Civil, 2013.

[9] CAMACHO, J. S. - Introdução ao Estudo do Concreto Armado - Faculdade de Engenharia de Ilha Solteira - Departamento de Engenharia Civil - Ilha Solteira-SP - 2006.

[10] IGLESIA, T. B. - Sistemas Construtivos em Concreto Pré-moldado - Universidade Anhembi Morumbi - São Paulo - 2006.

[11] MAKARI, J. M. S., DESNOYERS, R. P., McDONALD, S. E. - Centrifugal Casting Pipe - Institute for Research in Construction, National Research Council Canada, Ottawa, Ontario, Canada - June 2013. 